\title{
StORING PEANUTS IN GRAIN BAGS
}

\author{
Christopher L. Butts ${ }^{1, *}$, Jason K. Ward ${ }^{2}$ \\ ${ }^{1}$ USDA, ARS, National Peanut Research Laboratory, Dawson Georgia, USA. \\ 2 D. S. Weaver Labs NA, North Carolina State University, Raleigh, North Carolina, USA. \\ *Correspondence: chris.butts@usda.gov.
}

\section{HighLIGHTS}

- Existing bag loading equipment may be used to load both in-shell and shelled oil stock peanuts.

- Grain bags can be loaded at $1.2 \mathrm{t} / \mathrm{m}$ of in-shell peanuts and $2.3 \mathrm{t} / \mathrm{m}$ of shelled oil stock peanuts.

- Existing extraction equipment requires modification to unload shelled oil stock peanuts due to poor flow characteristics.

- Grain bags not suitable for storing in-shell peanuts due to significant moisture migration and quality reduction under typical Georgia conditions.

\begin{abstract}
Edible grade farmers' stock peanuts and shelled oil stock peanuts were stored in hermetically sealed silo or grain bags to determine their suitability for short-term storage. The objectives of the study were to evaluate equipment for loading and unloading the grain bags, the capacity of the grain bags, and the changes in quality. In May 2015, approximately $90 \mathrm{Mg}$ of farmers' stock (in-shell) peanuts from the 2014 crop were unloaded from a commercial warehouse, transported to Dawson, Georgia, and loaded into two $2.7 \mathrm{~m}$ diameter grain bags. Similarly, $85 \mathrm{Mg}$ of shelled oil stock peanuts were loaded into two $2.7 \mathrm{~m}$ diameter grain bags. Farmers' stock bags were unloaded after 30 and 60-d storage. A vacuum extractor and a skid steer loader were used due to wet peanuts in the top of the bag. Both oil stock bags were unloaded after 60-d storage. A skid steer loader was used to unload the oil stock bags because shelled oil stock peanuts did not flow adequately to use the conventional bag extraction equipment. Oxygen content in the farmers' stock peanuts decreased from ambient levels (21\%) to an average of $8.6 \%$ after 15-d storage. After 20-d storage, the oxygen content in the oil stock had decreased to $14 \%$. A layer of high moisture peanuts due to moisture migration and subsequent condensation in the top of both of the farmers' stock bags resulted in the peanuts being unsuitable for human consumption and reduced the value from $\$ 342 / \mathrm{Mg}$ to approximately $\$ 125 / \mathrm{Mg}$ for oil stock, a $63 \%$ reduction in value. No moisture problems were observed in the oil stock bags when they were unloaded. Based on these studies, sealed grain bags would be unsuitable for temporarily storing farmers' stock peanuts under typical Georgia conditions. Sealed grain bags could possibly be used to store oil stock peanuts for $60 \mathrm{~d}$, but suitable unloading equipment would have to be found or developed.
\end{abstract}

Keywords. Grain bag, Groundnut, Handling, Hermetic, Peanut, Silo bag, Storage.

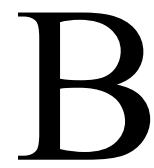
etween 1980 and 2010, annual peanut production in the United States averaged 1.76 million $\mathrm{Mg}$. Between 2011 and 2015, an average of 2.36 million $\mathrm{Mg}$ of peanuts were produced annually with a historic maximum of 2.82 million $\mathrm{Mg}$ produced in 2015 (USDA-NASS, 2016). This increase in production filled conventional storage capacity and made it necessary to develop additional storage facilities. The conventional

\footnotetext{
cC)(1) $\Theta$ The authors have paid for open access for this article. This (c) ${ }_{\mathrm{BY}} \mathrm{NC}$ ND work is licensed under a Creative Commons AttributionNonCommercial-NoDerivatives 4.0 International License https://creative commons.org/licenses/by-nc-nd/4.0/.

Submitted for review on 12 January 2021 as manuscript number PRS 14475; approved for publication as a Research Brief by the Processing Systems Community of ASABE on 15 November 2021.

Mention of company or trade names is for description only and does not imply endorsement by the USDA. The USDA is an equal opportunity provider and employer.
}

farmers' stock peanut warehouse is a metal frame building measuring $24.3 \mathrm{~m}$ wide, with a $7.3 \mathrm{~m}$ eave height with a 12:12 roof pitch (APSA, 2015). The typical farmers' stock warehouse has a capacity of approximately $85 \mathrm{Mg} / \mathrm{m}$ of length when the warehouse is filled to within $0.3 \mathrm{~m}$ of the eave (Butts, 2009). Six to eight months are required to construct new farmers' stock warehouse at a cost of $\$ 125$ to $\$ 150 / \mathrm{Mg}$. Peanut shellers leased non-traditional warehouse facilities storing peanuts in much shallower depths (4.5 to $5.5 \mathrm{~m})$ with a larger footprint $(46 \times 67 \mathrm{~m}$ typical $)$. At the flat storage facility, peanuts are emptied from the hopper onto a telescoping conveyor belt typically used for potato handling (Blankenship and Lamb, 1996) and loaded into the warehouse no deeper than $1.5 \mathrm{~m}$ on the exterior wall. The cost of building the flat storage is reported to be lower than conventional storage because of the minimal wall structure required to support the lateral pressure of the peanuts, and lower roof pitch $(<3: 12)$. 
Leading up to the record 2015 peanut crop, peanut buyers anticipated a large inventory carryover of farmers' stock peanuts from the 2014 crop. New warehouses could not be constructed in time for the 2015 harvest and warehouse space available for lease was limited. Options for temporary storage facilities were needed.

Grain or silo bags have been used to store commodities such as canola, corn, soybean, and wheat. The grain bag is a multi-layer flexible tube with limited permeability to water vapor and oxygen. The end of the tube is heat sealed and folded under itself, then using custom filling equipment, the grain is loaded into the bag, while compressing most of the air from the commodity. Once the bag is filled, the end of the tube is sealed and rolled up on itself. The respiration of the grain and any other organisms in the bag consume the oxygen within the bag, making a low oxygen atmosphere within the bag.

Ward and Davis (2012) stored corn and soybean in grain bags in Mississippi for 20 and 16 weeks, respectively. Analysis of corn samples before and after 20 weeks of storage showed no significant changes in average moisture, total damaged kernels, nor heat damaged kernels. After storing soybean for 16 weeks, the moisture content increased by $1.7 \%$ w.b. and total damaged kernels increased $3.7 \%$. One hopper of beans was docked $\$ 2.84 / \mathrm{m}^{3}$ due to being sour. An instrumentation system was used to monitor temperature and relative humidity in horizontal and vertical linear arrays within a filled and sealed grain bag (Ward and Davis, 2013). They observed that the vapor pressure calculated from the temperature and relative humidity tended to be higher in the center of the bag and lower near the bag edge, indicating moisture migration from the center toward the bag edge. Jian et al. developed models to estimate the soil temperature beneath a silo bag (Jian et al., 2015a) and the conditions inside the silo bag filled with canola (Jian et al., 2015b). Their simulation results showed that under Canadian Prairie conditions, moisture migration and condensation were most likely to occur during the spring and summer. The simulations also showed the location of the increased grain moisture content was somewhat dependent on initial moisture content of the canola.

The literature reporting the use of grain bags for storing peanuts is nonexistent.

\section{OBJECTIVES}

Due to successful storage of other commodities, particularly corn, in the southeastern U.S., a trial was undertaken to examine the potential use of grain bags to store farmers' stock and shelled oil stock peanuts. The objective of this study was to determine the suitability of conventional bag loading/unloading equipment for use with farmer' stock and shelled oil stock peanuts, measure bag capacity, and evaluate quality changes in storage.

\section{Materials ANd Methods}

A commercial peanut sheller located in Dawson, Georgia, USA, provided the farmers' stock peanuts for testing. Farmers' stock peanuts harvested in 2014 were stored in a conventional bulk storage facility according to standard industry practice from Fall 2014 until May 2015. On 5 and 6 May 2015, as the farmers' stock peanuts were unloaded from the bulk storage facility and transported to the shelling plant, four loads totaling approximately $80 \mathrm{Mg}$ were diverted for use in this study. Upon arrival at the test site, located in Dawson, Georgia, three samples were obtained from each load and graded using a pneumatic probe according the sampling protocol by the Federal-State Inspection Service (USDA-AMS, 2003). Recorded grade factors include percent foreign material (FM), loose shelled kernels (LSK), total sound mature kernels (TSMK), other kernels (OK), and damaged kernels (DK). The peanuts were transferred into a grain cart (X-treme 1015, Unverferth Mfg. Co., Kalida, Ohio). A gently-sloped grassed site was selected to minimize risk of puncturing the bag and the risk of standing rainwater. A gravity-flow bag loader was chosen (Stuffer M \& S SILOGRAIN Energia Zero, Martinez y Staneck, Buenos Airies,

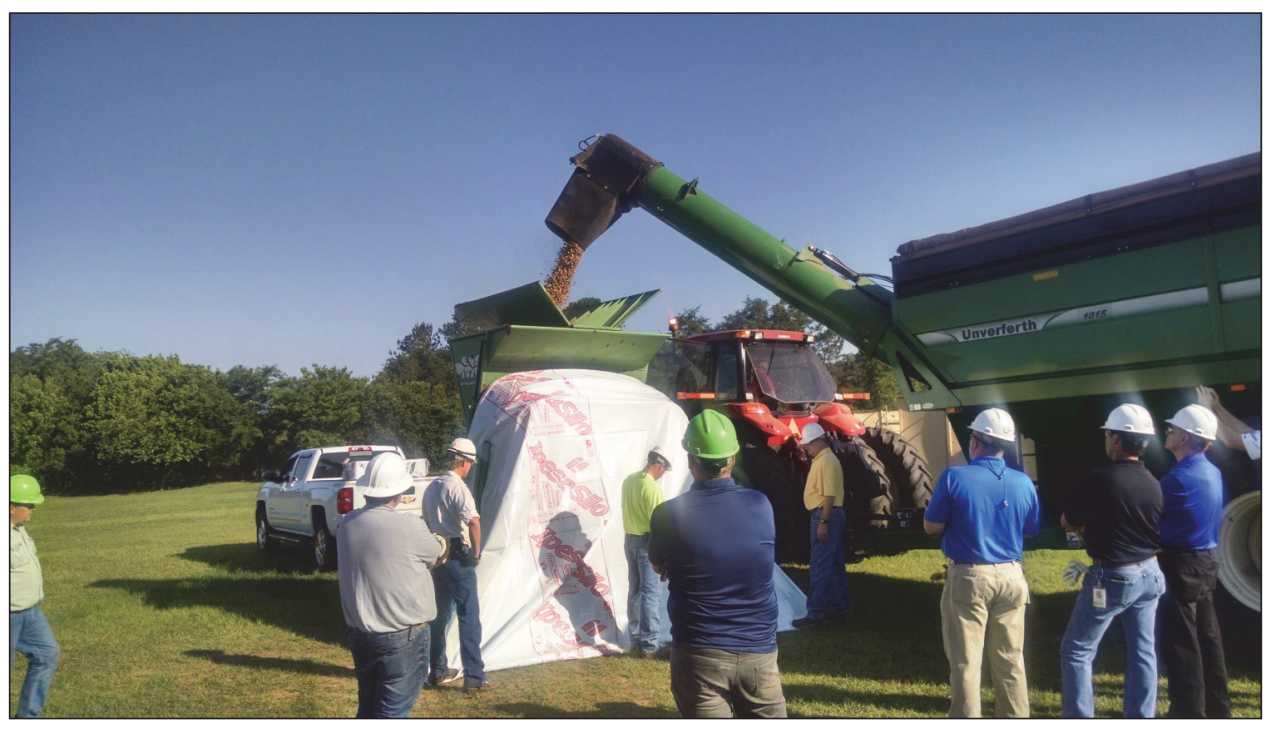

Figure 1. Filling the grain bag with farmers' stock peanuts, May 2015. 
Argentina) for conducting these tests. A $2.7 \mathrm{~m}$ diameter grain bag was positioned on the gravity-flow bag loader and prepared for loading. While transferring the peanuts from the grain cart into the bag loader (fig. 1), three samples of peanuts were caught as they exited the grain cart auger and graded using the same protocol as the initial samples. After loading approximately $45 \mathrm{Mg}$ (two trucks) into a single grain bag (FS-1) on 5 May 2015, excess bag material was pulled from the loading chute, cut, heat-sealed, and the end rolled back under itself. A second grain bag (FS-2) was loaded with the remaining two truckloads of farmers' stock peanuts on 6 May 2015 (table 1).

Similarly, four loads of shelled oil stock peanuts were shipped from shelling plants to the peanut oil mill located in Dawson, Georgia, were diverted for testing. Two trucks containing high oleic peanuts were loaded into the first grain bag (OS-1). The second oil stock bag (OS-2) was filled with shelled peanuts having a normal oleic fatty acid profile. Three samples of peanuts from each truckload of oil stock was obtained as the peanuts were discharged from the grain cart into the bag loader. Oil stock samples were analyzed for free fatty acids (FFA), peroxide values (PV), and aflatoxin.

Previous research has shown that the LSK, damaged kernels (DK), and other kernels (OK) are the components within a load of farmers' stock peanuts that have the highest risk of aflatoxin contamination (Dorner and Cole, 1997). The LSK, DK, and OK were retained from each of the farmers' stock grade samples and tested for aflatoxin using an immunoassay fluorescence method.

After loading, a probe was inserted horizontally into the bag with five Type $T$ thermocouples spaced every $31 \mathrm{~cm}$ beginning $15.3 \mathrm{~cm}$ from the outside edge of the bag and three relative humidity sensors (HM1500LF, Measurement Specialties, Hampton, Va.) spaced at $62-\mathrm{cm}$ intervals. This is the same horizontal probe used by Ward and Davis (2013). Dataloggers recorded the temperature and humidity in each grain bag every $4 \mathrm{~h}$ throughout the storage period. The oxygen $\left(\mathrm{O}_{2}\right)$ concentration inside each grain bag was measured at approximately one-third of the length of the bag from the East end, the center, and one-third of the length of the bag from the West end in each grain bag by inserting the probe for the handheld $\mathrm{O}_{2}$ analyzer (Model GP02, GrainPro Inc., Concord, Mass.). Oxygen concentration was measured at loading (5-6 May) and on 21 May, 29 May, 10 June, and 6 July 2015. Samples were retrieved on the same days as $\mathrm{O}_{2}$ sampling to monitor the peanut quality by cutting a slit in the grain bag, inserting a $51 \mathrm{~mm}$ diameter suction tube from a shop vac into the bag (fig. 2). All penetrations through the bag were repaired using a 10 mil PVC tape.

After a 30-d storage period, one of the farmers' stock bags (FS-2) was opened and unloaded using a pneumatic peanut

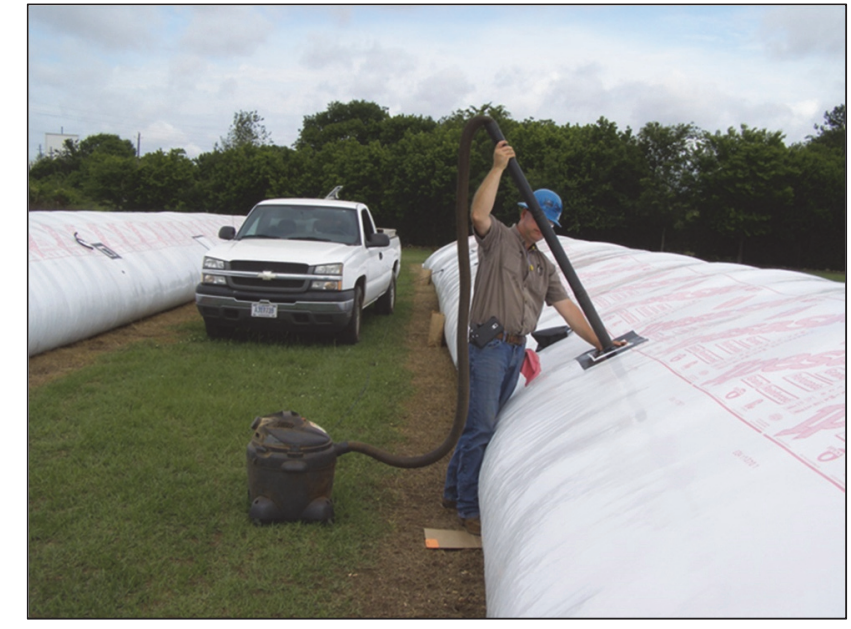

Figure 2. Using a shop vac to extract samples from grain bags filled with farmers' stock peanuts.

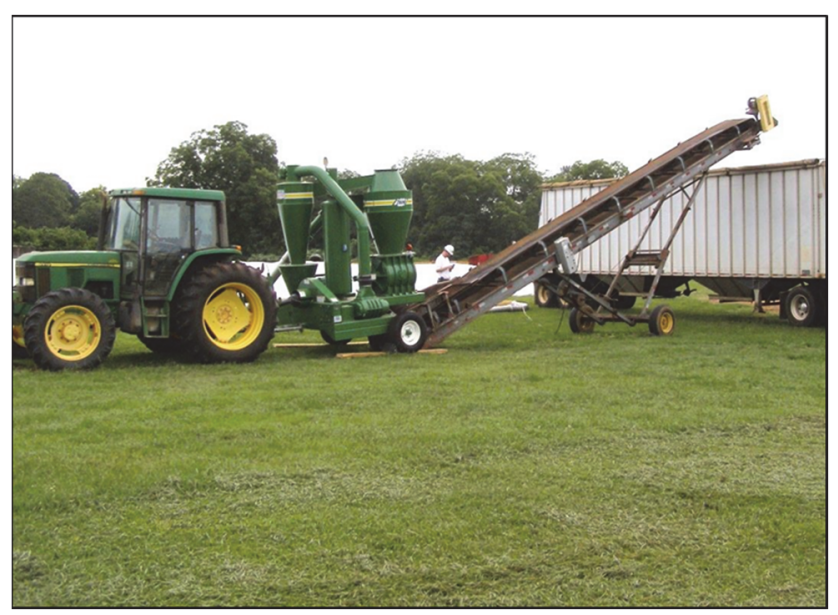

Figure 3. PTO-driven pneumatic equipment set up for unloading farmers' stock peanuts from grain bags.

handling system (7614DLX Peanut-VAC, Walinga, Guelph, Ontario, Canada) to transfer the peanuts from the grain bag to a truck (fig. 3). Each truck was weighed, and three farmers' stock grade samples were obtained for grade and aflatoxin analysis.

After 60 days in storage, the remaining bag of farmers' stock peanuts (FS-1) was unloaded, samples obtained, and analyzed. An attempt was made to use the pneumatic conveying system, but due to improper adjustment and operator error, the machine clogged. To maintain the unloading schedule, a skid-steer loader was used to complete the loadout of the second farmers' stock grain bag.

Both shelled oil stock bags (OS-1 and OS-2) were unloaded after $60 \mathrm{~d}$ of storage on 6 July 2015. Truck weights

Table 1. Peanut loading data for farmers' stock and shelled oil stock peanuts into grain bags.

\begin{tabular}{|c|c|c|c|c|c|c|c|c|}
\hline \multirow[b]{2}{*}{ Material } & \multirow[b]{2}{*}{ Bag } & \multirow[b]{2}{*}{ Fill Date } & \multirow[b]{2}{*}{ Unload Date } & \multirow{2}{*}{$\begin{array}{c}\text { Storage Time } \\
\text { (d) }\end{array}$} & \multirow{2}{*}{$\begin{array}{c}\text { Peanut Weight } \\
(\mathrm{kg})\end{array}$} & \multirow{2}{*}{$\begin{array}{c}\text { Bag Length } \\
(\mathrm{m})\end{array}$} & \multicolumn{2}{|c|}{ Bag Capacity } \\
\hline & & & & & & & $(\mathrm{Mg} / \mathrm{m})$ & $(\mathrm{m} / \mathrm{Mg})$ \\
\hline \multirow{3}{*}{$\begin{array}{c}\text { Farmers' } \\
\text { stock }\end{array}$} & FS-1 & 5 May 2015 & 7 July 2015 & 63 & 46160 & 42.7 & 1.08 & 0.92 \\
\hline & FS-2 & 6 May 2015 & 10 June 2015 & 35 & 44010 & 33.5 & 1.31 & 0.76 \\
\hline & Total & & & & 85470 & 76.2 & 1.18 & 0.85 \\
\hline \multirow{3}{*}{ Oil stock } & OS-1 & 5 May 2015 & 7 July 2015 & 63 & 42320 & 18.0 & 2.35 & 0.42 \\
\hline & OS-2 & 6 May 2015 & 8 July 2015 & 63 & 43150 & 19.2 & 2.25 & 0.45 \\
\hline & Total & & & & 85470 & 37.2 & 2.30 & 0.44 \\
\hline
\end{tabular}


were recorded and three samples from each truck were obtained to measure free fatty acids, peroxide values and aflatoxin. The initial goal was to use conventional extraction equipment (fig. 4) to extract the shelled oil stock peanuts from the grain bags. The extractor was installed, and operation initiated. However, the extremely poor flow characteristics of the shelled oil stock peanuts prevented the peanuts from flowing into the transfer augers and caused severe bridging, eventually causing the grain bag to tear. Therefore, the skid-steer loader was used to unload the oil stock peanuts from the bags.

The peanut value was calculated for the farmers' stock peanuts using the 2017 USDA Loan Schedule and based on the recorded farmers' stock grade factors. The gross loan value ( $\mathrm{GLV}, \$ / \mathrm{Mg}$ ) is calculated by:

$$
G L V=\$ 5.347 * \% T S M K+\$ 1.543 * \% O K
$$

where

$\% \mathrm{TSMK}=$ percent total sound mature kernels,

$\% \mathrm{OK}=$ percent other kernels.

The net loan value (NLV, $\$ \mathrm{Mg}$ ) is calculated by subtracting the deductions $(\$ / \mathrm{Mg})$ for excessive foreign material $\left(\operatorname{ded}_{f m}\right)$, damaged kernels $\left(\operatorname{ded}_{d m g}\right)$, and split kernels $\left(\operatorname{ded}_{s s}\right)$ (eq. 2). Clemson University Extension has published an online peanut loan value calculator for all market types and multiple crop years (Peanut Loan Rate Calculator, 2021) for additional information.

$$
N L V=G L V-\operatorname{ded}_{f m}-\operatorname{ded}_{d m g}-\operatorname{ded}_{s s}
$$

Data were statistically analyzed by comparing the mean observed quality factors within the same bag on separate sampling dates using a standard least squares analysis of variance (JMP v13, SAS Institute, Cary, N.C.).

\section{RESULTS AND DISCUSSION \\ EQUIPMENT PERFORMANCE}

Neither farmers' stock nor shelled oil stock peanuts flow like grains or oilseeds, such as corn, wheat, or soybean. The dynamic angle of repose of clean, dry farmers' stock peanuts

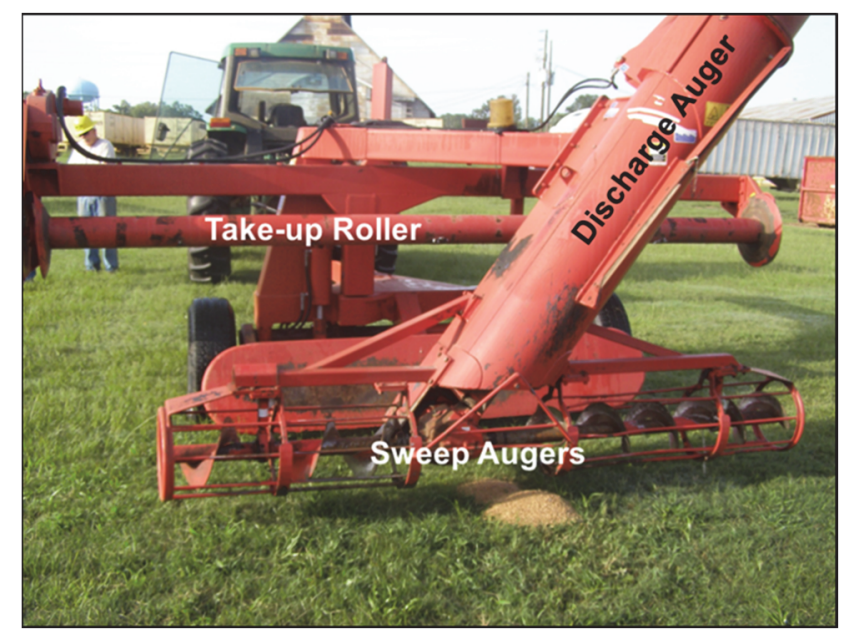

Figure 4. Extraction equipment for unloading material from grain bags. is approximately $33^{\circ}$ (Davidson et al., 1982) compared to $16^{\circ}$ for shelled corn and soybean (Boac et al., 2010). The angle of repose for shelled oil stock peanuts has not been documented in the literature, but the material has a high percentage of broken kernels and meal and generally does not flow well. The only modification of the equipment was the removal of a set of dividers (fig. 5) in the loading hopper intended to improve the distribution of the grain as it flowed into the bag. Four grain bags were filled on 5-6 May 2016. The total weight $(\mathrm{kg})$ of peanuts loaded into each bag and the total length $(\mathrm{m})$ of each bag were recorded and the bag capacity $(\mathrm{t} / \mathrm{m})$ was calculated (table 1$)$.

A truck was used to guide the bag loader as it filled. Normally, the pressure of the grain flowing into the bag pushes the truck and the loader with the brakes on the loader set to provide back pressure to load the bag properly. However, the hydraulic brake system on the loader was not functional and the peanut flow was inconsistent, requiring the truck driver to manually operate the brakes on the truck to coordinate the forward movement of the truck and bag loader with the tractor operator to properly fill the bag and maintain their direction. The bag fill rate was lowest on the first bag of farmers' stock $(1.08 \mathrm{Mg} / \mathrm{m})$. The second farmers' stock bag was filled at a rate of $1.3 \mathrm{Mg} / \mathrm{m}$ of length. The inconsistency of fill rate was due to inexperience of both the truck and tractor operators. The two oil stock bags averaged $2.3 \mathrm{Mg} / \mathrm{m}$. The fill rate on both oil stock bags was more consistent, $\pm 0.05 \mathrm{Mg} / \mathrm{m}$, compared to $\pm 0.11 \mathrm{Mg} / \mathrm{m}$ for the farmers' stock bags.

Farmers' stock bag 2 was opened on 10 June 2015 after 30 -d storage. Upon opening, a strong sour odor was detected, and soggy peanuts were observed approximately $15 \mathrm{~cm}$ deep and $1 \mathrm{~m}$ wide at the top of the bag the entire length of the bag (fig. 6). A considerable amount of condensate was observed on the inside of the grain bag suggesting that moisture migration had occurred in the bag and collected near top of the bag. There was apparently no visible mold, just discolored peanuts that were wet to touch with extremely soft shells. The peanuts in the remainder of the pile were dry with no visible signs of excessive moisture.

The peanut vac was used to remove the wet peanuts from the top of the pile and loaded into wagons for drying (fig. 7).

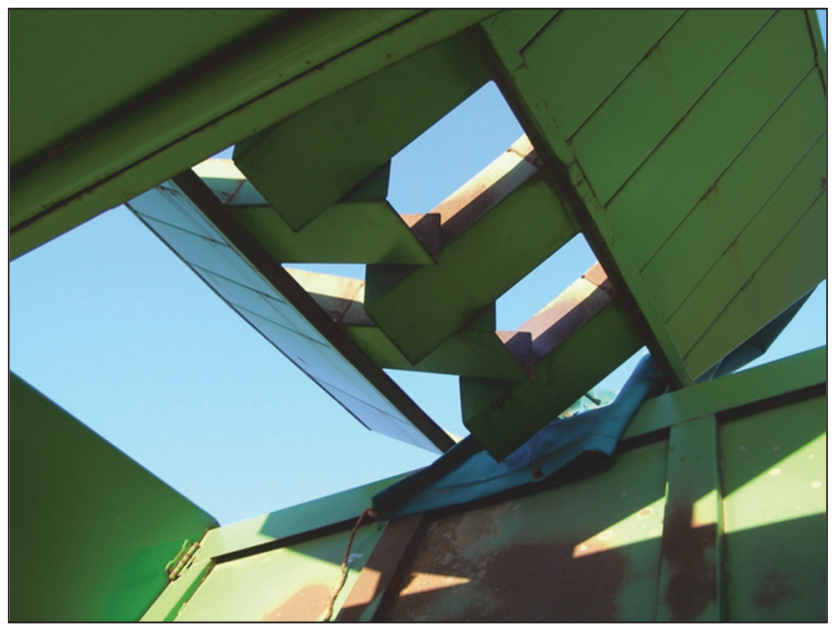

Figure 5. Fill hopper of bag loader prior to removal of diverter for use with peanuts. 


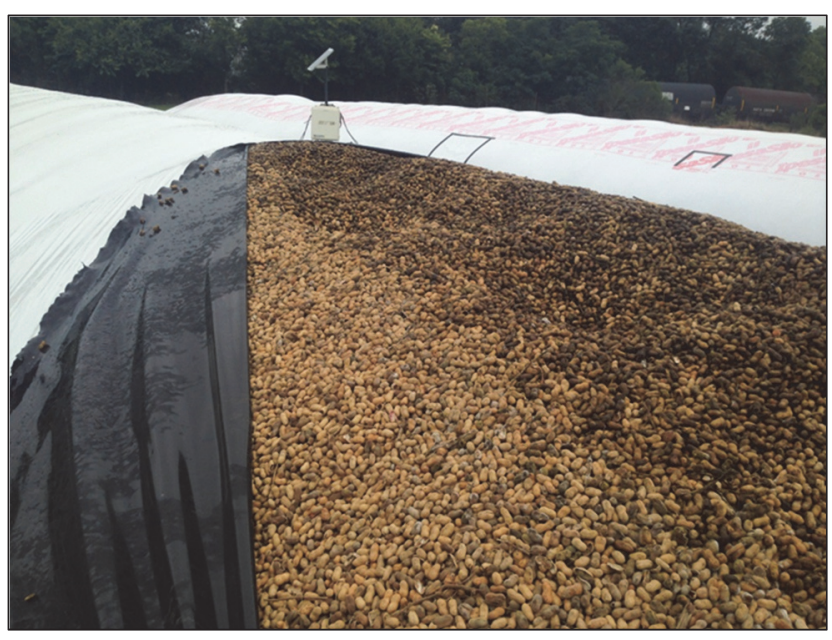

Figure 6. Peanut condition upon opening grains storage bag after 30-d storage.

Approximately $7350 \mathrm{~kg}(16 \%)$ of peanuts were removed and segregated for drying. The moisture content of the wet peanuts was not determined. After skimming the soured peanuts from the entire length of the bag, the remaining peanuts were discharged into waiting semi-trailers. The peanuts were deemed unsuitable for human consumption due to the odor and potential microbial damage and transported directly to the oil mill for shelling and crushing for oil. After drying, the peanuts from the top of the bag were taken to the oil mill for processing.

Farmers' stock bag 1 (FS-1) and the oil stock bag 2 (OS2) were unloaded on 7 July 2016 and oil stock bag 1 (OS-1) was unloaded on 8 July 2015 . When farmers' stock bag 1 was opened, similar conditions were observed as when FS-2 was opened $30 \mathrm{~d}$ earlier. The cooperator sent the peanuts directly to the oil mill for shelling and processing, and therefore, there was no need to separate the wet peanuts from the dry. Unloading began with the peanut vac, but due to improper clearance on the airlock blade tips, the vac clogged and required several hours to clear. Therefore, the remaining farmers' stock peanuts were unloaded from the grain bag

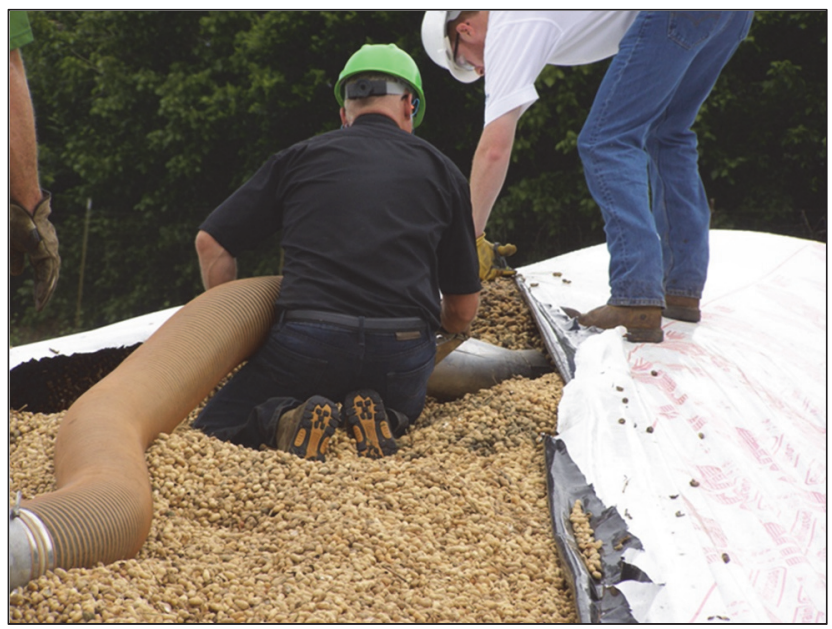

Figure 7. Using a peanut vac to remove the top high moisture layer of farmers' stock peanuts from the peanuts after 30-d storage in a grain bag. using a skid-steer loader, which is the conventional method of loading farmers' stock peanuts out of a warehouse.

The plan was to unload the oil stock bags using the conventional bag unloader shown in figure 4 . When unloading grains from the storage bags, the grain flows easily into the sweep augers and is transported to central discharge auger. Some material is pushed through the open bars toward the bottom of the bag. The tension on the take-up roller causes that material to flow back into the auger. As the bag is rolled up on the take up roller, the unloader and tractor are pulled into the bag. However, the oil stock peanuts do not flow like the grains typically stored in the bags. As the unloader progressed into the bag, peanuts accumulated between the bottom of the bag on the take-up roller and the sweep augers (fig. 8) preventing the unloader from moving into the main pile of peanuts. There was enough resistance to the unloader moving into the peanuts that the tractor with 4WD engaged could not push the unloader into the pile. Also, the leading face of the peanut pile resulted in a vertical face and would not flow into the sweep augers. Eventually, the bag was torn due to excessive tension on the roller. Therefore, both bags of oil stock peanuts were unloaded with a skid-steer bucket loader.

\section{Peanut Quality and Internal Bag Conditions}

The indicators of peanut quality in the farmers' stock grade are the percent foreign material (FM), LSK, the sound mature kernels (SMK), and sound splits (SS). The percent FM and LSK are calculated as a percent of the total material in a representative sample. The LSK are those peanuts that have been shelled during the process of harvesting, handling, and transportation prior to reaching the shelling plant and are valued the same as oil stock peanuts $(\$ 0.15 / \mathrm{kg})$. High levels of LSK indicate considerable mechanical damage in the harvesting and handling processes. The percent SMK and SS are the whole and split, respectively, kernels without visual damage presented as a percent of the weight of intact in-shell peanuts. The intention of grain bag storage is for the oxygen concentration within the bag to decrease due to the respiration of the product and any other living organisms sealed in the bag. Previous research (Butts et al., 2008) observed that

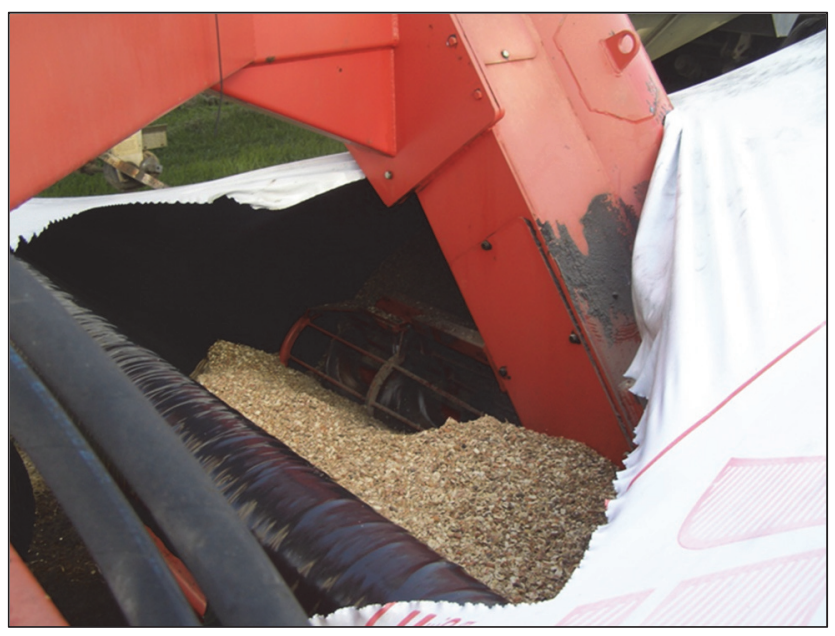

Figure 8. Attempting to unload shelled oil stock peanuts from a grain bag using conventional unloading equipment. 
oxygen concentration in low moisture peanuts stored in a hermetic container decreased to $6 \%$ after $180 \mathrm{~d}$ of storage. However, they also observed that the oxygen concentration decreased to approximately $2 \%$ in $15 \mathrm{~d}$ when the initial moisture content was approximately $9 \%$.

Oxygen concentration in both farmers' stock bags decreased from $21 \%$ to an average of $12 \%$ in $14 \mathrm{~d}$. After $30 \mathrm{~d}$ in storage, the $\mathrm{O}_{2}$ levels in the farmers' stock bags averaged 7.8\% (fig. 9). Oxygen concentration in farmers' stock bag 1 remained relatively constant for the second 30-d storage period.

The oxygen concentration in the oil stock bags decreased at a much slower rate. After 2 weeks of storage, the $\mathrm{O}_{2}$ concentration had decreased from $21 \%$ to $19 \%$. After $30 \mathrm{~d}$ of storage, the $\mathrm{O}_{2}$ concentration had decreased to an average of $10 \%$ in the two oil stock bags. However, the two were markedly different. The oxygen concentration in oil stock bag 1 was approximately $12 \%$ compared to $7 \%$ in oil stock bag 2 after 30 days. At the end of the 60-d storage test, both oil stock bags had an average $\mathrm{O}_{2}$ concentration of $10 \%$.

The slower $\mathrm{O}_{2}$ depletion in the oil stock bags than in the farmers' stock bags was likely due to a lower respiration rate of the shelled oil stock peanuts. The oil stock peanuts had already been shelled and during the shelling process, many of the peanuts were split causing the most biologically active portion of the kernel, the germ or embryo, to detach from the kernel.

The shape of the $\mathrm{O}_{2}$ depletion curves (fig. 9) are similar to that simulated for wheat stored in grain bags (Abalone et al., 2011). The $\mathrm{O}_{2}$ concentration decreases rapidly due to the respiration of the material in the bag. As the internal $\mathrm{O}_{2}$ concentration decreases, $\mathrm{O}_{2}$ diffuses from the outside ambient air into the bag and the $\mathrm{O}_{2}$ concentration stabilizes as the consumption rate equilibrates with the infiltration rate. The $\mathrm{O}_{2}$ concentration stabilized in the farmers' stock storage bags around 28 May and 10 June in the oil stock bags. The standard deviation of the three $\mathrm{O}_{2}$ measurements was approximately $4 \%$ after $15 \mathrm{~d}$ in storage on 21 May and decreased to $1 \%$ or less on the subsequent measurements. These measurements verify the assumption of uniform distribution of $\mathrm{O}_{2}$ made by Abalone et al. (2011).

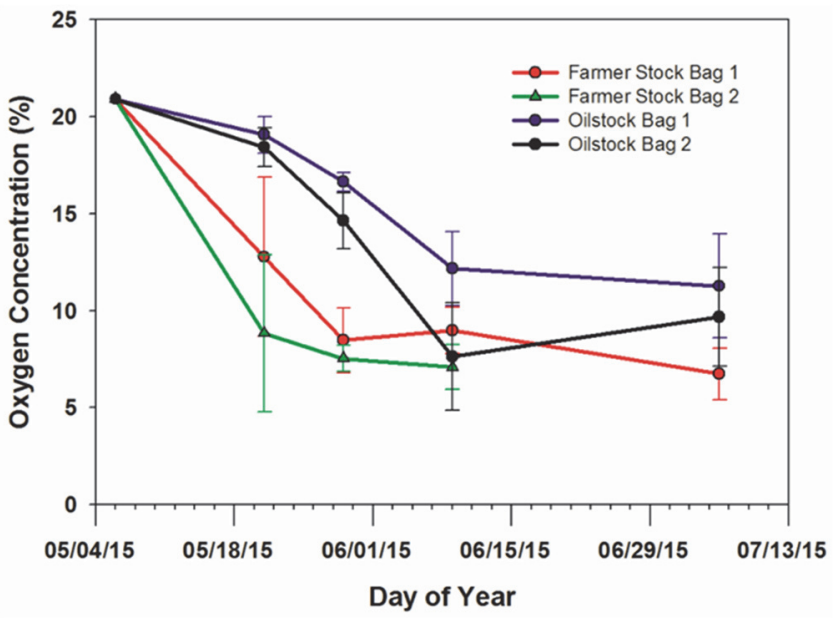

Figure 9. Oxygen concentration (\%) measured using a handheld $\mathrm{O}_{2}$ meter in grain bags used to store farmers' stock and oil stock peanuts. Data points and error bars represent the mean $\mathrm{O}_{2} \pm \sigma$.
The daily mean ambient temperature during the 60 -d storage period from 6 May to 8 June 2015 (FS-1, OS-1 and OS2) was $25^{\circ} \mathrm{C}$. The maximum temperature during the $60-\mathrm{d}$ storage period was $37^{\circ} \mathrm{C}$ and the minimum was $12^{\circ} \mathrm{C}$. The first $30 \mathrm{~d}$ of the storage period (FS-2) was slightly cooler with an average daily mean temperature of $24^{\circ} \mathrm{C}$ and a maximum temperature of $33^{\circ} \mathrm{C}$.

The mean temperatures measured 15,76 , and $137 \mathrm{~cm}$ from the edge of the bag were $25.2^{\circ} \mathrm{C}, 25.1^{\circ} \mathrm{C}, 24.6^{\circ} \mathrm{C}$, respectively, during the 30-d storage in farmers' stock bag 2 . The standard deviation of the temperature $15 \mathrm{~cm}$ from the edge was $3.6^{\circ} \mathrm{C}$ compared to $1.1^{\circ} \mathrm{C}$ at 76 and $137 \mathrm{~cm}$ from the edge of the bag. Similar trends for the relative humidity in farmers' stock bag 2 were observed. The relative humidity averaged $75 \%$ at all locations measured, but the standard deviation at $15 \mathrm{~cm}$ from the edge of the bag was $10 \%$ compared to approximately $1 \%$ at 76 and $137 \mathrm{~cm}$. Similar trends were observed during the 60-d storage in farmers' stock bag 1 . The variability in temperature, especially near the surface of the bag, could drive moisture migration and subsequent condensation on the interior of the bag, or at least regions of higher relative humidity. Since there was no vertical sensor probe monitoring the temperature and humidity, this can only be speculation. However, an average relative humidity of $75 \%$ indicated that the water activity of the bag interior was about 0.75 and conducive to microbial growth and rapid reduction in $\mathrm{O}_{2}$ concentration.

The peanut kernel equilibrium moisture content (d.b.) was calculated from the observed relative humidity using the Modified Halsey equation (ASABE Standards, 2007) then converted to wet basis (EMC). The EMC of the peanuts in farmers' stock bag 1 exceeded $10 \% 15 \mathrm{~cm}$ from the bag edge for $3 \%$ of the 60 -d storage period, but was never above $14 \%$ (fig. 10). The EMC at $15 \mathrm{~cm}$ from the edge of the bag averaged $7.2 \%$, compared to $6.5 \%$ and $8.0 \%$ at 76 and $137 \mathrm{~cm}$ from the edge, respectively. Based on the calculated average EMC of $7.2 \%$, minimal problems with excessive moisture were anticipated at unloading. However, a vertically

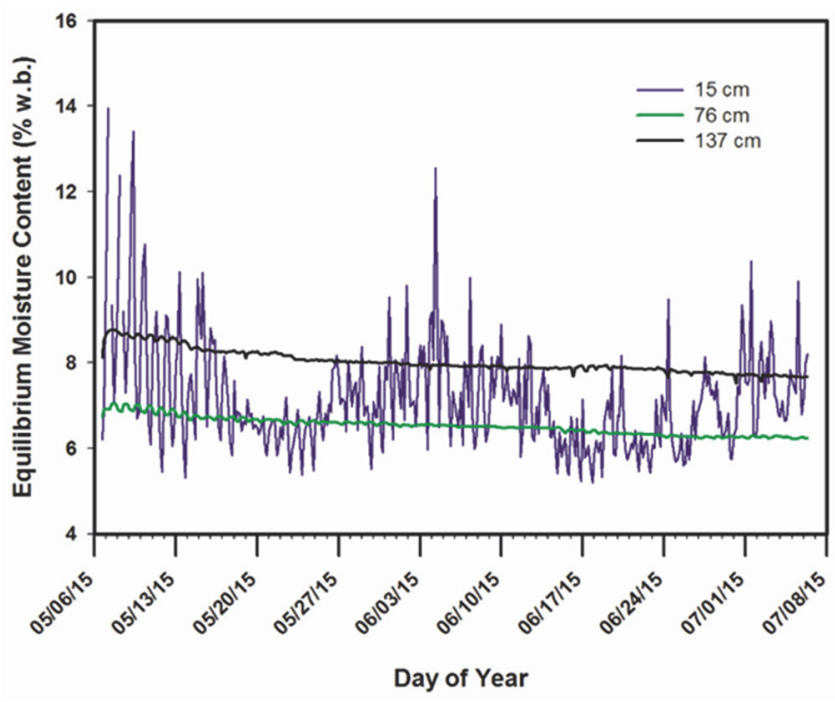

Figure 10. Equilibrium moisture content (w.b.) calculated using the relative humidity measured in farmers' stock peanuts stored for $60 \mathrm{~d}$ in farmers' stock bag 1. 
oriented sensor probe may have indicated the moisture migration that was observed when the bags were unloaded.

The average kernel moisture content of peanuts loaded into farmers' stock bag 1 from the grain cart was 5.7\% (table 3) and ranged from $5.7 \%$ to $5.9 \%$. However, the average moisture content of the peanut kernels upon arrival on site on the trucks and prior to unloading into the grain cart was $6.8 \%$ and is $1.1 \%$ higher than observed when sampled from the grain cart. This difference was likely due to sampling and was not anticipated because there was no real cause for drying during the transfer from the trucks through the dump pit onto a conveyor and into the grain cart. There should have been no significant air flow or heating during this transition process. The average kernel moisture content after unloading farmers' stock bag 1 was $6.8 \%$ and ranged from $5.7 \%$ to $7.3 \%$.

The estimated EMC in farmers' stock bag 2 averaged $8.0 \%$ throughout the $30-\mathrm{d}$ storage period. Approximately $13 \%$ of the storage time, the EMC exceeded $10 \%$ and occasionally exceeded $20 \%$ (fig. 11). The EMC increased from $7.7 \%$ at $137 \mathrm{~cm}$ to $8.0 \%$ at $76 \mathrm{~cm}$ and $8.4 \% 15 \mathrm{~cm}$ from the edge of the bag. The calculated EMC indicated that excessive moisture near the edge of the grain bag was a possibility. The calculated EMC at $76 \mathrm{~cm}$ was very stable, lacking even small diurnal fluctuations as observed at $137 \mathrm{~cm}$. This may indicate a faulty connection or faulty temperature/RH sensor at $76 \mathrm{~cm}$. The kernel moisture content upon arrival at the test site in trucks averaged 7.1\%. Samples after transferring from the grain cart into the bag loader averaged 5.8\%. This trend was like that observed on the peanuts loaded into bag 1 . The average moisture content of the peanuts after unloading was $6.3 \%$ and ranged from $5.7 \%$ to $6.7 \%$. This was considerably lower than the $8.0 \%$ average EMC estimated for the peanuts in farmers' stock bag 2 . This difference could be due to the layer of wet peanuts $(\sim 7300 \mathrm{~kg})$ was extracted and placed in a peanut drying wagon separate from the dry peanuts and were not included in the post storage sampling. Agreement between the EMC and final samples obtained from farmers'

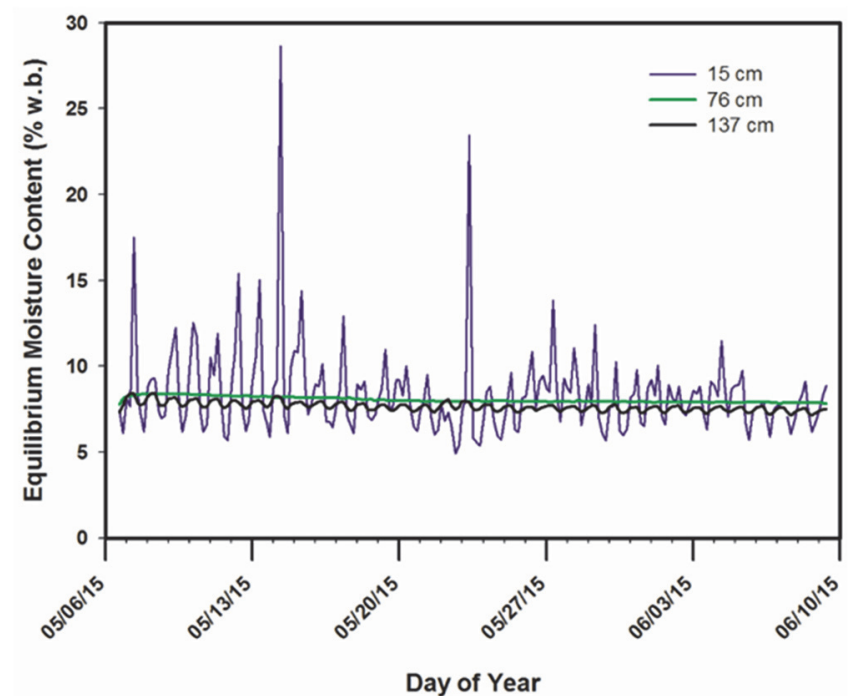

Figure 11. Equilibrium moisture content (w.b.) calculated using the relative humidity measured in farmers' stock peanuts stored for $30 \mathrm{~d}$ in farmers' stock bag 2. stock bag 1 was better because the wet layer of peanuts was not segregated from the dry peanuts since they were taken directly to the oil mill.

As indicated previously, there was a layer of high moisture peanuts approximately $15 \mathrm{~cm}$ deep and $1 \mathrm{~m}$ wide along the top of the grain bag and extending its full length. The affected peanuts had a very soft texture and were wet to touch. The boundary of the wet peanuts did not extend down the side. Having a probe inserted vertically as in previous research by Ward and Davis (2013) in addition to the horizontal probe would likely have clearly indicated the formation of this high moisture layer along the top of the bag.

The farmers' stock peanuts used in this study had equilibrated with the conditions during 7 months conventional farmers' stock storage between harvest and the initiation of this study and were approximately $7 \%$ moisture content. So, this study represents a best-case scenario relative to the potential moisture related problems. New crop peanuts that had not yet equilibrated would most likely experience worse moisture related problems than observed in this study.

The grade factors for the farmers' stock peanuts upon arrival in the truck (stage $=1$ ), exiting the grain cart auger (stage $=2$ ), $30 \mathrm{~d}$ after storage through the side wall of the bag (stage=3), and after unloading from the grain bag on the truck for transport to final destination (stage $=4$ ) are shown in table 2. The loose shelled kernels (LSK) and the foreign material (FM) were expected to increase between stages 1 and 2 due to the auger transport from the grain cart into the bag loader. The LSK in the first bag were numerically higher after stage $2(6.7 \%)$ than at stage $1(4.9 \%)$. In farmers' stock bag 2 , the LSK apparently decreased from $8.5 \%$ to $6.3 \%$ after being unloaded from the truck and into the grain bag. However, there were no statistically significant differences in the percent LSK or FM at any stage in the process for either grain bag. While loading farmers' stock bag 2 , the tractor operator reduced the grain cart auger rpm by reducing the tractor rpm to match the grain cart discharge rate to that of the material flowing into the grain bag. This apparently reduced the amount of mechanical damage on the peanuts. The only significantly different grade factors observed were the moisture content in farmers' stock bag 2 and the percent DK in bag 1 . The percent DK doubled between bag loading $(1.5 \%)$ and unloading (3.1\%).

The other grade factors, SMK, SS, and OK are grade factors determined by sizing peanut kernels after removing the hulls from a $500 \mathrm{~g}$ sample. These grade factors are used to determine the base value of the peanuts. Deductions are then subtracted for damaged kernels in excess of $2 \%$ and splits greater than $4 \%$. No significant difference in the loan value were observed, however, the value of the peanuts from FS-1 were $\$ 10 / \mathrm{Mg}$ lower in value when unloaded than when they were placed in the bag.

There were some significant changes in the chemical characteristics of the farmers' stock peanuts stored in the grain bags (table 3 ). Peroxide values and free fatty acids are indicators of oxidation of the oil in the peanut as the peroxide values and the free fatty acids both increase as oxidation occurs (Tiemstra, 1973). There were no detectable changes in the peroxide values of the farmers' stock peanut stored in bag $2(0.17 \mathrm{meq} / \mathrm{kg})$. However, the peroxide values of the 
Table 2. Mean ${ }^{[a]}$ farmers' stock grade factors for inshell peanuts at various stages of grain bag storage.

\begin{tabular}{|c|c|c|c|c|c|c|c|c|c|}
\hline Bag & Stage $^{[\mathrm{b}]}$ & $\begin{array}{l}\text { Foreign } \\
\text { Material }\end{array}$ & $\begin{array}{l}\text { Loose Shelled } \\
\text { Kernels }\end{array}$ & $\begin{array}{c}\text { Moisture } \\
\text { Content }\end{array}$ & $\begin{array}{l}\text { Sound Mature } \\
\text { Kernels } \\
(\%)^{[\mathrm{c}]}\end{array}$ & $\begin{array}{l}\text { Sound } \\
\text { Splits }\end{array}$ & $\begin{array}{c}\text { Other } \\
\text { Kernels }\end{array}$ & $\begin{array}{l}\text { Damaged } \\
\text { Kernels }\end{array}$ & $\begin{array}{c}\text { Farmers' Stock } \\
\text { Loan Value } \\
(\$ / \mathrm{t})\end{array}$ \\
\hline \multirow[t]{4}{*}{1} & 1 & 4.7 & 4.9 & 6.8 & 65.8 & 4.8 & 4.3 & $1.5^{\mathrm{b}}$ & 380.26 \\
\hline & 2 & 3.5 & 6.7 & 5.7 & 64.2 & 6.9 & 4.2 & $1.5^{\mathrm{b}}$ & 380.67 \\
\hline & 3 & 6.0 & 7.9 & 7.1 & 63.6 & 5.4 & 4.5 & NR & 361.96 \\
\hline & 4 & 5.5 & 7.2 & 6.8 & 63.2 & 5.8 & 5.0 & $3.1^{\mathrm{a}}$ & 370.79 \\
\hline \multirow[t]{4}{*}{2} & 1 & 4.2 & 8.5 & $7.1^{\mathrm{A}}$ & 69.3 & 5.9 & 3.1 & 0.8 & 403.34 \\
\hline & 2 & 2.9 & 6.3 & $5.8^{\mathrm{C}}$ & 68.4 & 6.9 & 3.2 & 0.6 & 403.90 \\
\hline & 3 & 4.0 & 9.3 & $6.4^{\mathrm{B}}$ & 62.0 & 6.9 & 3.1 & NR & 364.43 \\
\hline & 4 & 3.7 & 6.0 & $6.3^{\mathrm{C}}$ & 68.3 & 6.3 & 3.7 & 0.5 & 401.74 \\
\hline
\end{tabular}

[a] Means in the same column for the same grain bag are significantly different $(\alpha=0.05)$ if followed by differing uppercase letters; No letter $=$ No significant difference; NR $=$ Not Rated.

[b] Stages are identified as $1=$ pneumatic sample from the truck upon arrival at the test site prior to offloading into grain cart, $2=$ sampled after emptied from the grain cart into the grain bag, $3=$ sample extracted through side of bag after 30 -d storage, $4=$ pneumatic sample after unloading bag into truck at the end of the test

[c] Foreign Material and Loose Shelled Kernels shown as a percentage of total sample weight; Sound Mature Kernels, Sound Splits, and Other Kernels shown as percentage of weight of clean in-shell peanuts; Moisture Content is wet basis kernel moisture content.

Table 3. Mean ${ }^{[a]}$ peroxide values, free fatty acids, and aflatoxin contamination of farmers' stock peanuts stored in grain bags.

\begin{tabular}{|c|c|c|c|c|c|c|}
\hline \multirow[b]{2}{*}{ Bag } & \multirow[b]{2}{*}{ Stage $\mathrm{e}^{[\mathrm{b}]}$} & \multirow{2}{*}{$\begin{array}{c}\text { Peroxide } \\
\text { Values } \\
(\mathrm{meq} / \mathrm{kg})\end{array}$} & \multirow{2}{*}{$\begin{array}{l}\text { Free } \\
\text { Fatty } \\
\text { Acids } \\
(\%)\end{array}$} & \multicolumn{3}{|c|}{ Aflatoxin } \\
\hline & & & & Mean & $\begin{array}{l}\text { Maximum } \\
\text { (ppb) - }\end{array}$ & Minimum \\
\hline \multirow[t]{3}{*}{1} & 1 & $0.19^{\mathrm{A}}$ & 0.14 & ND & ND & ND \\
\hline & 2 & $0.10^{\mathrm{B}}$ & 0.13 & 88 & 350 & ND \\
\hline & 3 & $0.13^{\mathrm{B}}$ & 0.12 & 102 & 510 & ND \\
\hline \multirow[t]{3}{*}{2} & 1 & 0.19 & $0.08^{\mathrm{B}}$ & ND & ND & ND \\
\hline & 2 & 0.16 & $0.12^{\mathrm{AB}}$ & 7 & 20 & ND \\
\hline & 3 & 0.17 & $0.14^{\mathrm{A}}$ & 4 & 11 & ND \\
\hline
\end{tabular}

[a] Means in the same column for the same grain bag are significantly different $(\alpha=0.05)$ if followed by differing uppercase letters; No letter $=$ No significant difference; ND = Below Detectable Limits

[b] Stages are identified as $1=$ pneumatic sample from the truck upon arrival at the test site prior to offloading into grain cart, $2=$ sample extracted using a shop vac through side of bag after 30 -d storage, $3=$ sample extracted using a shop vac through the side of the bag after 60d storage immediately prior to opening the bag.

peanuts stored in bag 1 apparently decreased from $0.19 \mathrm{meq} / \mathrm{kg}$ at loading to an average of 0.13 and $0.12 \mathrm{meq} / \mathrm{kg}$ for bags FS-1 and FS-2, respectively. There was no difference in peroxide value of the peanut samples obtained using the shop vac and those obtained from the final grade after unloading. In research to examine the shelf life of peanuts, Mozingo et al. (2004) used a maximum allowable peroxide value of $20 \mathrm{meq} / \mathrm{kg}$ to determine when the peanuts were no longer acceptable. The samples from the farmers' stock bags never exceeded the maximum allowable peroxide value of $20 \mathrm{meq} / \mathrm{kg}$ in this study, but these samples did not include peanuts from the re-wetted portion of the bags.

Sanders et al. (1981) stated that the percent free fatty acids (FFA) are an indicator of hydrolytic rancidity quite possibly due to mold growth. They also stated that the normal range is $0.2 \%$ to $0.6 \%$ FFA with values near the lower end of that range being ideal. The percent FFA remained below $0.2 \%$ throughout the storage in both bags.

The aflatoxin levels for the all loads of farmers' stock peanuts were below detectable limits when initially loaded into the grain bags. Aflatoxin contamination increased in both bags after $30 \mathrm{~d}$. In bag 2, the samples taken with the shop vac the day before the bags were unloaded had an average aflatoxin contamination of $7 \mathrm{ppb}$ and ranged from 20 $\mathrm{ppb}$ to below detectable limits. Similar results were obtained with the samples collected during unloading with the peanut vac. The samples averaged $4 \mathrm{ppb}$ and ranged from non-detectable to $11 \mathrm{ppb}$. Neither sets of samples included the wet peanuts from the top of the bag. When the shop vac probe was inserted into the grain bag 2 , it was inserted below any detectable condensation at a $45^{\circ}$ angle down toward the ground. When samples were obtained during unloading, they were obtained from the hopper trailers using the farmers' stock pneumatic sampler. The wet peanuts had been segregated onto peanut drying trailers so that they could be dried prior to transporting to the shelling plant and oil mill. Had these peanuts not had the objectionable odor, once the wet peanuts were segregated using the peanut vac, these peanuts could have entered the edible market. Action limits for aflatoxin in edible product is $20 \mathrm{ppb}$ (USDA-AMS, 2004).

When grain bag FS-1 was sampled after 30-d storage (Stage 3 ), the aflatoxin contamination averaged $88 \mathrm{ppb}$ and ranged from non-detectable to $350 \mathrm{ppb}$. This was much higher than that sampled from bag 2 and indicated that the some of the wet peanuts had caused mold growth and aflatoxin production during storage. The mean aflatoxin of the peanuts sampled at 60-d storage was slightly higher at $102 \mathrm{ppb}$ than the 30 -d sample. Aflatoxin concentration after 60 -d storage ranged from non-detectable to $510 \mathrm{ppb}$. Based on these data, the peanuts from the farmers' stock bag 1 were correctly directed to the oil mill.

The oil stock peanuts placed in OS- 1 were peanuts that had an elevated proportion of oleic fatty acid. High oleic (Hi $\mathrm{O} / \mathrm{L})$ peanuts are defined as having an oleic (C18:1) to linoleic (C18:2) ratio of $\geq 9: 1$ compared to $2: 1$ for normal oleic peanuts. Since oleic acid is more completely saturated than linoleic fatty acid it is likely to have a lower oxidation rate than linoleic fatty acid. Therefore, the $\mathrm{Hi} \mathrm{O} / \mathrm{L}$ peanuts should have less oxidation than the normal $\mathrm{O} / \mathrm{L}$ peanuts stored in oil stock bag 2 (Davis et al., 2016).

The peroxide values for all shelled oil stock peanuts were less than $0.20 \mathrm{meq} / \mathrm{kg}$ when loaded into the two storage bags (fig. 12) and remained less than $0.30 \mathrm{meq} / \mathrm{kg}$ throughout the $60-\mathrm{d}$ storage period. The peroxide values for the high $\mathrm{O} / \mathrm{L}$ peanuts stored in bag 1 remained at below $0.20 \mathrm{meq} / \mathrm{kg}$ for the duration of the test. The peroxide values for the normal $\mathrm{O} / \mathrm{L}$ peanuts stored in bag 2 spiked at an average of $0.29 \mathrm{meq} / \mathrm{kg}$ after $30 \mathrm{~d}$ in storage. However, these values 


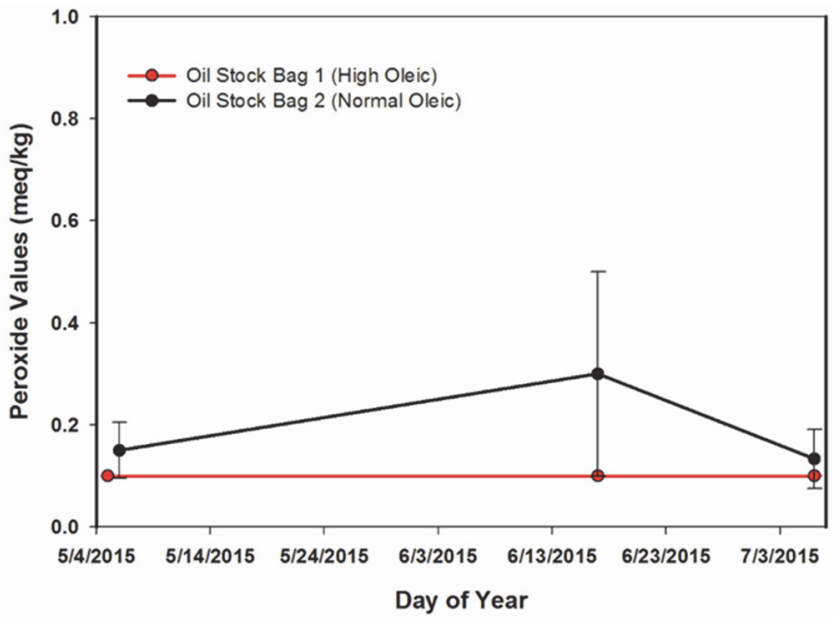

Figure 12. Peroxide values (meq/kg) for shelled oil stock peanuts stored for $60 \mathrm{~d}$ in grain storage bags. Data points and error bars represent the mean peroxide values $\pm \sigma$.

were all well below the $20 \mathrm{meq} / \mathrm{kg}$ and changes were insignificant during storage.

The percent FFA were approximately $2 \%$ and above the normal range of $0.6 \%$ generally accepted for edible product. During storage the percent FFA increased in both grain bags (fig. 13). However, percent FFA in the high $\mathrm{O} / \mathrm{L}$ peanuts stored in bag OS-1 increased at a slower rate than the normal $\mathrm{O} / \mathrm{L}$ peanuts stored in bag OS-2. After 60 -d storage, the percent FFA of the normal $\mathrm{O} / \mathrm{L}$ peanuts increased to an average of $7.9 \%$ and ranged from $5.2 \%$ to $11.3 \%$. The percent FFA of the high $\mathrm{O} / \mathrm{L}$ peanuts averaged $5.4 \%$ and ranged from $5.0 \%$ to $5.8 \%$ after 60 -d storage.

Based on previous research (Davis et al., 2016), the changes in PV and percent FFA were not unexpected. The high $\mathrm{O} / \mathrm{L}$ peanuts stored in bag 1 should have been more stable than the normal $\mathrm{O} / \mathrm{L}$ peanuts. The oil chemistry has not been reported to have any effect on the potential for aflatoxin contamination; therefore, changes in aflatoxin contamination should be similar in both grain bags storing the shelled oil stock peanuts. The aflatoxin concentration of peanuts sampled from both grain bags are shown over time in figure 14. The mean aflatoxin concentration in oil stock peanuts

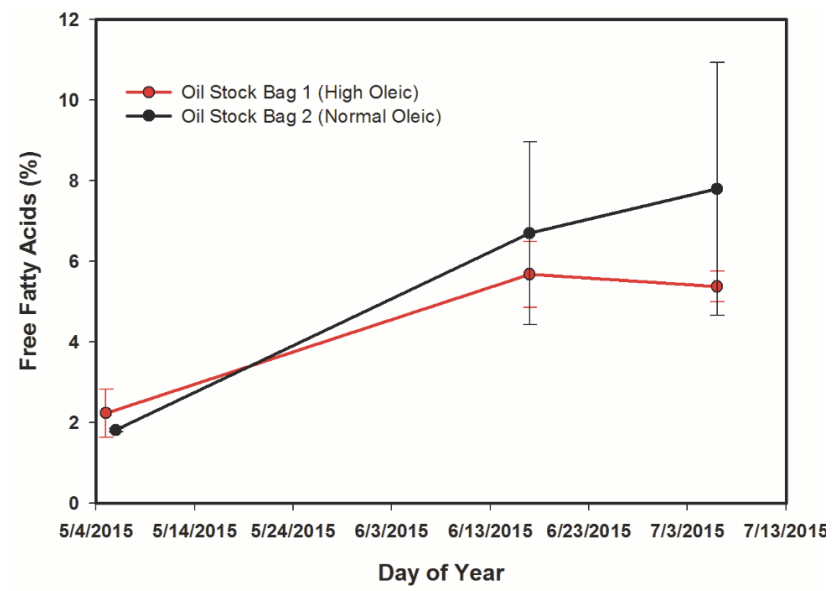

Figure 13. Percent free fatty acids of shelled oil stock peanuts stored in grain bags for $60 \mathrm{~d}$. Data points and error bars represent the mean percent free fatty acid $\pm \sigma$.

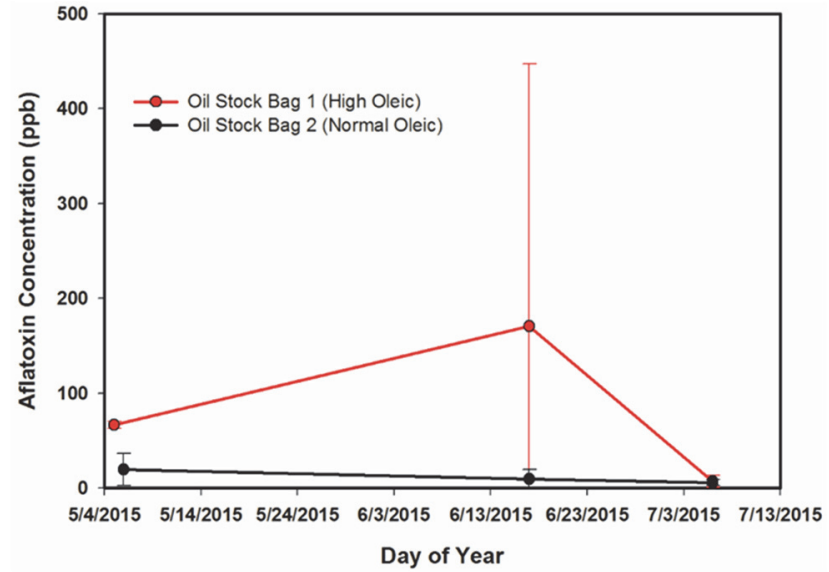

Figure 14. Aflatoxin contamination of samples retrieved from shelled oil stock peanuts stored in grain bags for $60 \mathrm{~d}$. Data points and error bars represent the mean aflatoxin concentration $\pm \sigma$.

initially loaded into bag 1 was $67 \mathrm{ppb}$. The samples retrieved after $30 \mathrm{~d}$ in grain bag 1 had an average concentration of $170 \mathrm{ppb}$. However, one of the three samples had an aflatoxin concentration of $490 \mathrm{ppb}$ compared to 8 and $13 \mathrm{ppb}$ for the other two samples. This demonstrates the highly variable distribution of aflatoxin contamination in a load. The samples retrieved from bag 1 after $60 \mathrm{~d}$ had an average aflatoxin concentration of $7 \mathrm{ppb}$. The aflatoxin concentration showed no change in bag 2 and averaged 6 ppb after 60 -d storage. No changes in aflatoxin contamination during the 60 -d storage trial could be detected in either grain bag using the sampling plan that was employed.

\section{CONCLUSION}

A study was undertaken to evaluate the feasibility of using grain bags for short term hermetic storage of farmers' stock and shelled oil stock peanuts. The goals were to evaluate the use of existing equipment for loading and unloading grain bags and to evaluate changes in peanut quality. Using a grain cart to transfer farmers' stock peanuts from the truck into the bag loader could cause an increase in loose shelled kernels. However, a grain cart can be used successfully if the speed of the transfer auger to move the peanuts from the grain cart into the bag loader is reduced to minimize damage. The grain cart successfully transferred the shelled oil stock peanuts. The gravity-flow bag loader was successfully used to load both farmers' stock and shelled oil stock peanuts into the grain bags. Farmers' stock peanuts were loaded at an average of $0.85 \mathrm{~m} / \mathrm{Mg}$ compared to an average $0.44 \mathrm{~m} / \mathrm{Mg}$ for shelled oil stock peanuts. The peanut vac was successfully used to unload one of the grain bags and provided the ability to segregate poor quality peanuts from better ones if necessary. However, proper adjustment was critical to successfully unloading the bag. Due to the poor flow characteristics of the shelled oil stock peanuts, the conventional bag unloader equipped with sweep augers pulling material toward a central discharge auger was unable to unload the peanuts from the grain bag. Operators resorted to using a skid steer loader to unload both oil stock grain bags and one farmers' stock bag. 
Moisture migrated and collected along the top of the bags storing farmers' stock peanuts causing an undesirable $15 \mathrm{~cm}$ $\times 1 \mathrm{~m}$ band of wet peanuts the entire length of the bag. Apparent microbial activity in the high moisture peanuts occurred causing the oxygen levels to decrease and a very offensive odor in the farmers' stock peanuts. The high moisture peanuts and the offensive odor rendered the peanuts unsuitable for human consumption and were diverted to the oil mill for crushing. The aflatoxin concentration increased in one of the grain bags from below detectable limits to an average greater than $100 \mathrm{ppb}$. Oil quality as indicated by peroxide values and percent free fatty acids of the farmers' stock peanuts was not changed during the storage trials.

The shelled oil stock peanuts had no significant changes in peroxide values during the 60 -d storage period, but hydrolytic oxidation did occur as indicated by the change in percent free fatty acids. As expected, the high oleic peanuts stored had a slower increase in percent free fatty acids than the normal oleic peanuts.

While the equipment performed satisfactorily for moving farmers' stock peanuts in and out of grain bags, storing farmers' stock peanuts in grain bags is not recommended because of deterioration of quality while stored in the bags. There were no similar issues relative to degradation of quality of shelled oil stock peanuts, but unloading the bags using existing bag unloaders was unsuccessful. Therefore, unless significant changes in unloading equipment, grain bag storage is not recommended for storing shelled oil stock peanuts.

\section{ACKNOWLEDGEMENTS}

The authors wish to express appreciation to the following individuals and entities for assistance in completing this research. Mr. Rick Harrell of Delta Grain Bag provided the bags, bag loader, and unloader for this study. Mr. Ken Swaving and Chuck Brothers, Walinga Pneumatic Conveying Systems, provided the prototype peanut vac for use during unloading. Golden Peanut and Tree Nuts located in Dawson, Georgia provided the peanuts, the test site and site maintenance, farmers' stock grading, chemical testing, and personnel for loading and unloading the grain bags. The authors thank Mr. Clyde Johnson and Mr. Dan Todd, Engineering Technicians at the USDA, ARS National Peanut Research Laboratory, for their assistance in collecting samples and data, and completion of this research.

\section{REFERENCES}

Abalone, R., Gaston, A., Bartosik, R., Cardoso, L., \& Rodriguez, J. (2011). Gas concentration in the interstitial atmosphere of a wheat silo-bag. Part i: Model development and validation. $J$. Stored Products Res., 47(4), 268-275. https://doi.org/10.1016/j.jspr.2011.05.004

APSA. (2015). Handling and storage of farmer stock peanuts. American Peanut Shellers Assoc. Retrieved from http://www.peanut-shellers.org/pdf/HandlingStorageManual.pdf

ASABE Standards . (2007). D245.6: Moisture relationships of plant-based agricultural products. St. Joseph, MI: ASABE.
Blankenship, P. D., \& Lamb, M. (1996). Handling farmer stock peanuts at warehouses wtih potato equipment. Peanut Sci., 23, 19-23. https://doi.org/10.3146/i0095-3679-23-1-4

Boac, J. M., Casada, M. E., Maghirang, R. G., \& Harner, J. P. (2010). Material and interaction properties of selected grains and oilseeds for modeling discrete particles. Trans. ASABE, 53(4), 1201-1216. https://doi.org/10.13031/2013.32577

Butts, C. L. (2009). Warehouse ventilation calculator. Washington, DC: USDA ARS. Retrieved from http://www.ars.usda.gov/Services/docs.htm?docid=7338

Butts, C. L., Dorner, J. W., Lamb, M. C., \& Sorensen, R. B. (2008). Storing peanuts in flexible hermetically sealed containers. ASABE Paper No.08-4198. St. Joseph, MI: ASABE.

Davidson, J. I., Whitaker, T. B., \& Dickens, J. W. (1982). Grading, cleaning, storage, shelling, and marketing of peanuts in the United States. In H. E. Pattee, \& C. T. Young (Eds.), Peanut sci. and tech. (pp. 571-623). Yoakum, TX: Am. Peanut Res. Educ. Soc., Inc.

Davis, J. P., Price, K. M., Dean, L. L., Sweigart, D. S., Cottonaro, J. M., \& Sanders, T. H. (2016). Peanut oil stability and physical properties across a range of industrial relevant oleic acid/linoleic acid ratios. Peanut Sci., 43(1), 1-11. https://doi.org/10.3146/0095-3679-43.1.1

Dorner, J. W., \& Cole, R. J. (1997). Distribution of aflatoxin in grade sample components of farmers stock peanuts. Peanut Sci., 24(1), 47-51. https://doi.org/10.3146/i0095-3679-24-1-11

Jian, F., Chelladurai, V., Jayas, D. S., \& White, N. D. (2015a). Three-dimensional transient heat, mass, and momentum transfer model to predict conditions of canola stored inside silo bags under Canadian prairie conditions: Part I. Soil temperature model. Trans. ASABE, 58(4), 1127-1134. https://doi.org/10.13031/trans.58.11052

Jian, F., Chelladurai, V., Jayas, D. S., \& White, N. D. (2015b). Three-dimensional transient heat, mass, and momentum transfer model to predict conditions of canola stored inside silo bags under Canadian prairie conditions: Part II. Model of canola bulk temperature and moisture content. Trans. ASABE, 58(4), 11351144. https://doi.org/10.13031/trans.58.11053

Mozingo, R. W., O'Keefe, S. F., Sanders, T. H., \& Hendrix, K. W. (2004). Improving shelf life of roasted and salted inshell peanuts using high oleic fatty acid chemistry. Peanut Sci., 31(1), 40-45. https://doi.org/10.3146/pnut.31.1.0009

Peanut Loan Rate Calculator. (2021). Clemson Cooperative Ext. Retrieved from https://precisionag.sites.clemson.edu/ Calculators/Peanut/LoanRate/

Sanders, T. H., Smith, J. S., Lansden, J. A., \& Davidson, J. I. (1981). Peanut quality changes associated with deficient warehouse storage. Peanut Sci., 8(2), 121-124. https://doi.org/10.3146/i0095-3679-8-2-11

Tiemstra, P. J. (1973). Determining the quality of raw peanuts and manufactured products. In Peanuts - culture and uses (pp. 603656). Stillwater, OK: Amer. Peanut Res. Educ. Assoc.

USDA-AMS. (2003). Farmers' stock peanuts inspection instructions. Washington, DC: USDA-AMS.

USDA-AMS. (2004). Milled peanuts inspection instructions. Washington, DC: USDA-AMS Fruit and Vegetable Divison.

USDA-NASS. (2016). Quick Stats. Washington, DC: USDANASS. Retrieved from http://quickstats.nass.usda.gov/

Ward, J. K., \& Davis, J. D. (2012). Effects of grain bag internal environmnet of commercial corn and soybeans. ASABE Paper No. 121337534. St. Joseph, MI: ASABE.

Ward, J. K., \& Davis, J. D. (2013). A system to assess grain bag storage internal environment. Trans. ASABE, 56(4), 1503-1509. https://doi.org/10.13031/trans.56.9835 